\title{
Mindfulness Training led to Catharsis and Mindfulness-To-Meaning in a Patient with Social Anxiety Disorder Comorbid with Persistent Depressive Disorder (Dysthymia) - A Case Report with Patient's Personal Note -
}

Hisanobu Kaiya ( $\nabla$ kai@fuanclinic.com )

Hisanobu KAIYA https://orcid.org/0000-0002-8701-5015

\section{Asuka Hasegawa}

Tokyo Mindfulness Center

Chika Komatsu

Akasaka Clinic, Warakukai Medical Corporation

\section{Shota Noda}

Akasaka Clinic, Warakukai Medical Corporation

\section{Fusaka Minami}

Department of Neuropsychiatry, Keio University School of Medicine

\section{Philippe Goldin}

Clinically Applied Affective Neuroscience Laboratory, University of California Davis

\section{Yosuke Hasegawa}

Tokyo Mindfulness Center

\section{Case report}

Keywords: mindfulness, social anxiety disorder, persistent depressive disorder, experiential avoidance, catharsis, Mindfulness-To-Meaning, awareness, verbalization, positive reappraisal, decentering

Posted Date: October 12th, 2021

DOI: https://doi.org/10.21203/rs.3.rs-952519/v1

License: (a) (i) This work is licensed under a Creative Commons Attribution 4.0 International License. Read Full License 


\section{Abstract}

\section{Background:}

The use of mindfulness in the treatment of anxiety and depression is becoming more and more widespread, but there are few reports that it has fundamentally changed patients' sense of life.

\section{Case Presentation:}

This report showed 9 year's progress of treatment for Social Anxiety Disorder and Persistent Depressive Disorder in a 41year-old female patient experiencing a long-term painful married life with a carefree husband and controlling mother-in-law. During the past 25 months, she received 180 sessions of mindfulness training, resulting in complete remission of the anxiety and depression symptoms. After the 30th session she experienced an episode of the catharsis during the mindfulness training and experienced what can be called Mindfulness-To-Meaning, which is characterized by durable eudaimonic well-being in the face of adversity.

\section{Discussion and Conclutions:}

The psychological mechanisms that supported arriving at Mindfulness-To-Meaning were delineated as: Heightened (1) awareness which promoted (2) verbalization of the primary theme of suppression, in which the stress was (3) appraised metacognitively. Then (4) decentering permitted integrating this painful theme into a new adaptive self and world view, which resulted in (5) emotional catharsis, or release. Furthermore (6) positive appraisal of this experience enhanced awareness and led to the experience of (7) Mindfulness-To-Meaning .

\section{Background}

Social Anxiety Disorder (SAD) is a highly prevalent psychological problem [1] with high rates of comorbidity, especially with depressive disorders [2]. The clinical case shared in the present study entailed a patient who suffered from SAD comorbid with Persistent Depressive Disorder (PDD). SAD is characterized by experiential avoidance (EA) of different types of adversity $[3,4]$. EA is further considered to be a basis for the development of PDD [5].

Social anxiety is a clinical target that can be addressed with mindfulness training (MT), which has been shown to be as effective as cognitive behavioral therapy (CBT) [6,7]. EA has also been shown to be inversely related to dispositional mindfulness $[8,9]$. Furthermore, there is preliminary evidence that PDD can be treated successfully by MT $[10,11]$.

The present clinical case presentation describes the treatment course of a 41year-old female patient with primary SAD comorbid with PDD, who had EA in relation to a long-term painful marriage with a reckless husband and controlling mother-in-law. The prolonged EA and emotional suppression were resolved in a sudden cathartic release during MT. The long-term MT was associated with an experience of Mindfulness- 
to-Meaning (MTM), a durable form of positive affectivity and sense of meaningfulness in life in the face of adversity [12].

In this paper, we would like to show the trajectory of the psychological effects of MT, which induced not only full remission of the SAD and PDD, but also the state of MTM. We further discuss the psychological mechanisms of MT that may lead to and support MTM.

\section{Case Presentation}

Mrs. A is 41year-old Japanese housewife who presented with complaints of anthropophobia and feeling gloomy all day long.

\section{Life history}

She was brought up in luxury. However, her family was strict and included a rugged mother and despotic paternal grandmother with an elder brother. Her father was almost always working apart from her family. During kindergarten, she had separation anxiety and phobia for people with glasses. She had no intimate schoolmates and reported feeling disliked by classmates and teachers in her elementary school. During high school, she recoiled from being seen by others due to psoriasis which began at age 15 .

Her mother was an unyielding woman of spirit and an absolute monarch for her. The patient was entirely a compliant child. Just after graduation from a woman's college, she was forced into an arranged marriage with a man who was 9 years older. She could not express her own thoughts and wishes in her marriage. Thereafter, she experienced a stressful married life with a carefree husband who was a typical mother's boy and a strict parents-in-law. The mother-in-law was severely controlling. The patient lived only to serve her husband and parents-in-law. In these self-sacrificing days, the patient was blessed with the birth of two sons. She could not remember any pleasure during child rearing. She reported pretty severe alexithymia. Later her elder son refused to attend junior school and high school.

\section{Clinical History}

In the 2 years before the Mrs. A's first intake, she could hardly find the words to speak at Parent Teacher Association meetings. School negotiation about the refusal of her son was a great burden for her. One day at home she suffered a panic attack that caused great embarrassment in front of her mother-in-law. She was intensely concerned about her son.

\section{Findings, diagnosis and treatment plan in the first examination at May 2008}

By first intake, Mrs. A responded slowly and appeared depressed. She found it painful to talk with school administrators about her son. She ventured out of her home only when necessary due to fear of interacting with people in shops and on the streets or vehicles. She completed housework under the scrutiny of her parents-in-law. She reported that she never enjoyed life, had no appetite and sleep problems. 
Psychological assessment tools: The following self-report questionnaires were administered at her initial visit. State-Trait Anxiety Inventory, state anxiety (STAI-S)[13]: 51/80, trait anxiety (STAI-T)[13]: 57/80, Selfrating Depression Scale (SDS)[14] 46/80, Japanese version of the Liebowitz Social Anxiety Scale (J-LSAS) [15] 104/134, Social Anxiety Disorder Scale (SADS)[16] 48/150.

The patient experienced a panic attack on only one occasion. Her phobic fear in vehicles was not agoraphobic but rather interpersonal strain. Her primary diagnosis was SAD. The patient was experiencing low energy or fatigue, low self-esteem and feelings of hopelessness continuously over the last two years. Her comorbid psychiatric diagnosis was PDD.

The patient's treatment began with psychoeducation and pharmacological treatment. Fluvoxamine was given in an increment manner from $25 \mathrm{mg}$ to $100 \mathrm{mg}$ per day p.o. Furthermore, clonazepam for anticipatory anxiety and tension was prescribed as needed.

\section{Mindfulness Training (MT)}

There are two courses for mindfulness training at the Tokyo Mindfulness Center (TMC). One course is the standard Mindfulness-based Stress Reduction program (MBSR) developed by Jon Kabat-Zinn [17]. The other course is optional. Attendants can join when they like after an introductory education in mindfulness. Mindfulness class was open for 3 hours every day except Sunday. The mindfulness class was consisted of Hatha yoga for an hour, meditation, mainly calm abiding (Shamata in Sanskrit), for 30 minutes including loving-kindness meditation, then sharing for the remaining time. Participants were encouraged to engage in both formal and informal meditation practices each day. TMC offers one-day meditation retreats every month and seminars/lectures by internationally renowned guests. The fee of the practice is covered by health insurance for patients having chronic psychiatric disorders. MBSR was delivered by a team consisting of a long-term (15 years) Zen practitioner (HK), a qualified teacher of MBSR (YH), an official instructor of Mindfulness-Based Cognitive Therapy (CK), a yoga instructor (AH) and a clinical psychologist (SN). The patient also attended the optional course.

\section{Clinical course}

Two months after the beginning a selective serotonin reuptake inhibitor (Fluvoxamine), Mrs. A's interpersonal tensions decreased and her son began to attend school (July 2008). Her SAD symptoms reduction was 30\% (J-LSAS scores dropped from 104 to 72). After 7 years, her SAD symptoms decreased by $60.5 \%$ (J-LSAS scores dropped from $104 \rightarrow 41$ ). J-LSAS scores further decreased by 20 after she completed MT. However, her depressive mood did not improve (SDS scores: 36, 46, 38, 31, and 39 points (December 2015) (Fig.1).

The patient began to attend to the mindfulness class, however, she discontinued after several classes. After half of a year (8 years since her first intake, June 2016), the patient re-engaged in MT. She attended classes several times a week, earnestly. After the 30th sessions, she experienced a powerful emotional burst and flashback, that is, catharsis, during MT. She felt a release and she gradually began to feel more open and cheerful. She attended more than 160 mindfulness sessions times during 25 months including 
10 sessions of MBSR. Her social anxiety and depressive symptoms got to almost remission at the end of the treatment: J-LSAS; $104 \rightarrow 20$, SADS; $48 \rightarrow 9$, SDS; $46 \rightarrow 29$, STAI-S; $51 \rightarrow 33$, Freiburg Mindfulness Scale [18]; $26 \rightarrow 37$. Her clinical improvement continued for 3 years after the end of treatment (Fig. 1).

\section{Personal Report of Patient}

This report was written at December 26th, 2016 after 69th session of MT.

\section{[Rationale for starting mindfulness]}

It was suggested by my doctor. I'm in OK condition right now, but something deep down inside was off and I noticed a complete lack of a sense of self-affirmation. I was already in my 40s and thought l'd given things a try one more time.

\section{[The first change you became aware of]}

I stopped being angry.

\section{[Changes after you started mindfulness]}

\section{$<$ Times 1-20>2016/ June 13-September 23}

During this period, I developed the painless habit of waking up and coming to the TMC. I was extremely nervous about being around people I didn't know, and I felt really fatigued. When I spoke while sharing, I was nervous, had palpitations, my hands shook, and my voice quivered. I was cognizant of the distance between me and the people next to me, and I was resolute about maintaining my personal space. Once my breathing was controlled, I settled down and regained my composure. I felt my body go limp and instantly felt relaxed. I couldn't concentrate unless I closed my eyes.

\section{$<$ Times 21-40> 2016/September 24-November 1}

I got used to coming to the TMC, and I had a normal daily rhythm. down as a result of breathing. I felt my pulse with my fingertips, and I noticed a tingling sensation in my face, neck, and arms.

One day after the 30th session of MT when it was my turn to share, I suddenly began to cry uncontrollably for no apparent reason. As I share, "Every day is a struggle because I'm anxious to tell the doctor I'll be better soon. I really want to learn how to practice mindfulness, but I'm going around in circles. Although I'm trying, I'm starting to wonder if that [going around in circles] may just be it." I couldn't stop crying even after that. My emotions were gushing out of me, so I took a walk away from the TMC for 3 hours. While walking, I felt like I would throw up once I reached home, and I started having visions similar to flashbacks. The next morning, I was troubled by the feelings that arose in me, and I talked with Psychologist CK. As I explained, "I sensed something from my sudden outburst of emotion while sharing yesterday. Up till now, I had lived my life with the belief that 'nothing angers me,' 'I don't need anything,' and 'I can accept anything.' 
I thought that it didn't matter if I died now or at the age of 80 . I strove to convince myself to be happy that I'm fulfilling the mission I've been given. In other words, my feelings weren't needed in my life, and I've lived by resolutely determining to lock those feelings away deep down in my heart and to never let them out. But while sharing yesterday, those stifled emotions suddenly surfaced and I couldn't stop them from coming out because I didn't understand what was happening inside me. Afterwards, I had flashbacks and remembered images of past events like they were photos. I was never happy while raising my children and I anguished over whether I was unfit to be a mother, but I fondly recalled my eldest son in flashbacks and I recalled the joy and happiness I felt as our family grew when my second son was born. Photos from my childhood and school days depicted me striving to stifle an unfathomable anguish. As I continue to practice mindfulness, an energy "to live" has sprung out of my closed self." Psychologist CK informed me that this was a good sign and advised me to continue practicing mindfulness for the time being.

\section{$<$ Times 41-60> 2016/November 4-December 10}

प्राप्र Meditating in a seated position provides stability and a keen sense of the body and the inner state of the body (interoceptive awareness). One is also able to see things with the eyes half closed. After the 40th session of MT, I increasingly had unusual experiences with those around me. Up till now, my husband had curtly responded to my questions with just "I got it" or "Yeah," but surprisingly he began responding warmly, "That's right. We'll do that from now on". Conversations with my children lasted only as long as necessary, but they began contacting me, and we laughed aloud for the first time in decades. I had difficulty dealing with my local mothers' group, but I ran into them by chance and effortlessly greeted them with a smile instead of running away. One day, my mom wept with joy at something I said to her. I also experienced instances of communicating without speaking (telepathy experiment). What I was thinking that day is the exact same thing Instructor $Y H$ was thinking. I would ask Clinical Psychologist CK about something, only to return home and find it in a book I was reading. Or Psychiatrist HK would mention a technique to resolve a problem I had out of the blue.

\section{$<$ Times 61-160> 2016/December 12-2017/October 13}

My condition is stable, and I'm working sincerely and honestly trying to practice mindfulness each day. I strive to get up early and go to bed early each day, and I sit down at 4:30 AM in the morning. Unbelievably, I start moving around as soon as I wake up. प्वस्य Recently, I've felt the intense desire to help others and to make everyone happy rather than thinking of myself.

During this period, I've experienced mental states I had never experienced before, such as being surrounded by warmth and an absence of physical sensation.

Mindfulness has taught me the meaning of my life. Each person has a unique existence. Mindfulness is a way to truly sense the uniqueness of one's own existence. Since I started mindfulness, there has always been another self inside of me. The one who is living in the present as a physical body, and the one who can look down on it and judge things calmly at all times. 


\section{Discussion}

\section{Treatment Course}

Mrs. A's social anxiety dramatically improved after MT for 25 months. Mrs. A received CBT before MT which should have worked better for her because CBT strengthen cognitive abilities [19], increases positive affective empathy [20] and disputing of anxious thoughts and feelings via reappraisal in SAD [21]. Mrs. A's PDD symptoms fluctuated during pharmaco-therapy and CBT. Her depression improved steadily after beginning of the MT and finally arrived at remission. Three years after the end of treatment, Mrs. A's condition remained in complete remission of the two disorders and she was able to maintain a life of mindful well-being. (Fig. 1).

\section{Experiential avoidance (EA) and Catharsis}

Mrs. A had a severe self-sacrificing life with an absent husband and controlling mother in-law for 20 years. Mrs. A stated, "Up till now, I had lived my life with the belief that 'nothing angers me,' 'I don't need anything,' and 'I can accept anything.' I thought that it didn't matter if I died now or at the age of 80 . I strove to convince myself to be happy that I'm fulfilling the mission I've been given." This statement suggests experiential fusion, an automatic process whereby one becomes absorbed in contents of consciousness, leading to a diminished capacity to monitor and/or regulate psychological process. This state is thought to be a target of MT, which is thought to act via enhancing meta-awareness, perspective taking and cognitive reappraisal [22]. Another statement of Mrs. A, "my feelings weren't needed in my life, and I've lived by resolutely determining to lock those feelings away deep down in my heart and to never let them out." This also suggest EA, a trait-like tendency to avoid unpleasant internal experiences [23]. It is reported that dispositional mindfulness has antagonistic effects on EA [8,9].

A very limited aspect of this situation could be called alexithymia. Mrs. A's alexithymia seems to have been relieved by the long-term MT as reported by Bornemann \& Singer [24]. On the contrary, a brief MT had no significant effect on alexithymia [25]. In the present case, alexithymia was almost completely released by long-term MT.

Mrs. A's statement, "while sharing yesterday, those stifled emotions suddenly surfaced and I couldn't stop them from coming out because I didn't understand what was happening inside me. Afterwards, I had flashbacks and remembered images of past events like they were photos. I was never happy while raising my children and I anguished over whether I was unfit to be a mother, but I fondly recalled my eldest son in flashbacks and I recalled the joy and happiness I felt as our family grew when my second son was born." This suggests catharsis occurring 4 months after beginning MT. This refers, to the discharge of previously suppressed affects connected to traumatic events that occurs when these events are brought back into consciousness and reexperienced [26]. EA might be called suppression in the Floydian sense. Suppression is one of the defense mechanisms of Ego and called as repression by Freudian Psychoanalysis, which is a target of therapy using free association. Delmonte [27] pointed out similarities between cathartic release of emotional materials found during mindfulness meditation, and that found in the abreaction of free 
association. Meditation, like free association in psychoanalysis, would be thought as to facilitate the emergence of unconscious (sub-verbal) material and allow for its integration at a higher (more cognitive) level of awareness [28]. Furthermore, MT would cause catharsis by alteration of balanced dominance of the hemispheres, which reduces the default dissociation between hemispheres, offering verbal consciousness greater access to normally suppressed emotion [29]. In this way, the repressed emotion might be verbalized and catharsis occurs. Recent neuroimaging studies of mindfulness provided findings supporting these hypotheses in which morphometric changes in gray matter asymmetry [30] and increase in white matter projections [31,32] were shown.

\section{Mindfulness-to-Meaning Theory (MTM Theory)}

It might be meaningful to follow the changes in Mrs. A's psychological conditions after her catharsis. About 30 times of MT (after 4 months), Mrs. A experienced catharsis as an initial effect of the heightened awareness that would continue to grow during the entire MT period. Shortly after this catharsis, the memories that had been surrounded by negative emotions changed to memories with vivid and joyful emotions. This may say as posttraumatic growth, which refers to the psychological growth experienced in the course of challenges to the consequences of trauma and subsequent suffering. Trauma, as used here, is broader and more non-specific than the APA [33] definition of trauma [34]. Mrs. A's catharsis changes negative affect to positive one, this transformation of affect through MT requires a cognitive reappraisal that results from sufficiently expanded awareness [12].

About 50 times of MT (after 5 months), Mrs. A became more stable in the sitting position and began to feel a strong sense of physical and interoceptive sense during MT. At the same time, she had a strange experience and a telepathic experience. The acquisition of interoceptive sense in MT is said to be closely related to the disappearance of alexithymia [25]. Her strange and telepathic experience could be a prelude to a mystical experience seen in meditation.

After 60 times of MT (after half year), She wrote, "I have the feeling that I am living firmly grounded in my daily life. These days, it's not about me, but more about wanting to help the people around me and wanting everyone to be happy." MT went beyond the level of completely curing her anxiety and depression to lift her to the level of a well-being [35]. Furthermore, she became more prosocial and altruistic.

About 150 times of MT (after 1 year), Mrs. A described in the last part of her note as following, "Mindfulness has taught me the meaning of my life. Each person has a unique existence. Mindfulness is a way to truly sense the uniqueness of one's own existence". This is just a model of MTM Theory proposed by Garland et al. [12], as a model of mindfulness in the face of adversity to introduce a positive emotion regulation and ultimately allow a durable state having what is pleasant, growth promoting, or meaningful in life, a process which motivates values-driven behavior and engenders a deeper sense of purpose and self-actualization, that is to say, eudaimonic well-being, which is not hedonic approaches to happiness depending on obtaining pleasure and avoiding pain [36]. Garland et al. [37] studied the chronological evolution of psychological background from the start of MT to MTM in 107 SAD patients. The finding indicated increases in decentering by 3 months (corresponding to Mrs. A's catharsis after 4 months of MT), 
awareness of interoceptive sense by 6 months (corresponding to Mrs. A's acquisition of the sense after 5 months of MT) and increases in the use of reappraisal by 9 months culminating in greater positive affect at 12 months post-treatment (corresponding to Mrs. A's statement of MTM after 12 months of MT). The consistency of each of these occurring time of psychological facts over time between in their study and in our case is very interesting. Although Mrs. A arrived at MTM, She is one breath away from reaching the realm of self-transcendence [38]. It is considered that Mrs. A reached at the 5th Level of Engel's (1997) meditation depth scale (0-7), which state is shown as being uplifted (beginning synchronicity and absorption, new experiences of time and space).

In conclusion, the psychological mechanism to arrive at MTM in the present case was thought as followed: Heightened (1) attentions or awareness that would continue to grow during the entire MT period promotes (2) verbalizes the core of the main theme of suppression, where the stress is (3) reappraised. Then (4) decentering occurs processing and integrating the painful theme into new adaptive self and world, which appears as (5) catharsis. Furthermore (6) positive appraisal is matured in expanded awareness and finally reach at (7) MTM.

This case report showed exemplary effects of MT. It was the result of Mrs. A's very diligent mindfulness efforts, which cannot be applied to all patients with SAD.

\section{List Of Abbreviations}

SAD

Social Anxiety Disorder

PDD

Persistent Depressive Disorder

EA

Experiential Avoidance

MT

Mindfulness Training

CBT

Cognitive Behavioral Therapy

MTM

Mindfulness-to-Meaning

STAI-T

State-Trait Anxiety Inventory, State anxiety

STAI-S

State-Trait Anxiety Inventory, Trait anxiety

SDS

Self-rating Depression Scale

J-LSAS

Japanese version of the Liebowitz Social Anxiety Scale 
SADS

Social Anxiety Disorder Scale

TMC

Tokyo Mindfulness Center

MBSR

Mindfulness-based Stress Reduction program

APA

American Psychiatric Association

\section{Declarations}

\section{Ethics approval and consent to participate}

Written informed consent was obtained from the participant.

\section{Consent for publication}

Written informed consent was obtained from the participant.

\section{Availability of data and materials}

Data sharing is not applicable to this article as no datasets were generated or analyzed during the current study.

\section{Competing interests}

The authors have no competing interests to declare.

\section{Funding}

Not applicable.

\section{Authors' contributions}

MT was delivered by a team consisting of $\mathrm{HK}, \mathrm{YH}, \mathrm{CK}, \mathrm{AH}$ and $\mathrm{SN}$. FM and PG revised the draft of the manuscript. All authors approved the final version of the manuscript.

\section{Acknowledgements}

The authors would like to thank Mrs. Matsumoto for the preparation of the paper.

\section{Note}

This paper was presented as a presidential address at the 4th Japan Mindfulness Society in September 2019. 


\section{References}

1. Stein DJ, Lim CCW, Roest AM, de Jonge P, Aguilar-Gaxiola S, Al-Hamzawi A, Alonso J, Benjet C, Bromet EJ, Bruffaerts R, de Girolamo G, Florescu S, Gureje O, Haro JM, Harris MG, He Y, Hinkov H, Horiguchi I, Hu C, Karam A, Karam EG, Lee S, Lepine JP, Navarro-Mateu F, Pennell BE, Piazza M, Posada-Villa J, Ten Have M, Torres Y, Viana MC, Wojtyniak B, Xavier M, Kessler RC, Scott KM, WHO World Mental Health Survey Collaborators. The cross-national epidemiology of social anxiety disorder: Data from the World Mental Health Survey Initiative. BMC Med. 2017;15(1):143. https://doi.org/10.1186/s12916017-0889-2.

2. Koyuncu A, İnce E, Ertekin E, Tükel R. Comorbidity in social anxiety disorder: diagnostic and therapeutic challenges. Drugs Context. 2019;8:212573. https://doi.org/10.7573/dic.212573.

3. Kashdan TB, Farmer AS, Adams LM, Ferssizidis P, McKnight PE, Nezlek JB. Distinguishing healthy adults from people with social anxiety disorder: Evidence for the value of experiential avoidance and positive emotions in everyday social interactions. J Abnorm Psychol. 2013;122(3):645-55. https://doi.org/10.1037/a0032733.

4. Kashdan TB, Goodman FR, Machell KA, Kleiman EM, Monfort SS, Ciarrochi J, Nezlek JB. A contextual approach to experiential avoidance and social anxiety: Evidence from an experimental interaction and daily interactions of people with social anxiety disorder. Emotion. 2014;14(4):769-81. https://doi.org/10.1037/a0035935.

5. Barnhofer T, Brennan K, Crane C, Duggan D, Williams JMG. A comparison of vulnerability factors in patients with persistent and remitting lifetime symptom course of depression. J Affect Disord. 2014;152-154:155-61. https://doi.org/10.1016/j.jad.2013.09.001.

6. Koszycki D, Benger M, Shlik J, Bradwejn J. Randomized trial of a meditation-based stress reduction program and cognitive behavior therapy in generalized social anxiety disorder. Behav Res Ther. 2007;45:2518-26. https://doi.org/10.1016/j.brat.2007.04.011.

7. Goldin PR, Thurston M, Allende S, Moodie C, Dixon ML, Heimberg RG, Gross JJ. Evaluation of Cognitive Behavioral Therapy vs Mindfulness Meditation in Brain Changes During Reappraisal and Acceptance Among Patients With Social Anxiety Disorder: A Randomized Clinical Trial. JAMA psychiatry. 2021. https://doi.org/10.1001/jamapsychiatry.2021.1862.

8. Garland EL, Roberts-Lewis A. Differential roles of thought suppression and dispositional mindfulness in posttraumatic stress symptoms and craving. Addict Behav. 2013;38(2). https://doi.org/10.1016/j.addbeh.2012.02.004.

9. Riley B. Experiential Avoidance Mediates the Association Between Thought Suppression and Mindfulness with Problem Gambling. J Gambl Stud. 2014;30:163-71. https://doi.org/10.1007/s10899-012-9342-9.

10. Hamidian S, Omidi A, Mousavinasab SM, Naziri G. Comparison of the effect of mindfulness-based cognitive therapy accompanied by pharmacotherapy with pharmacotherapy alone in treating dysthymic patients. Iranian Red Crescent Medical Journal. 2013;15(3):239-44. https://doi.org/10.5812/ircmj.8024. 
11. Hamidian S, Omidi A, Mousavinasab SM, Naziri G. The Effect of Combining Mindfulness-Based Cognitive Therapy with Pharmacotherapy on Depression and Emotion Regulation of Patients with Dysthymia: A Clinical Study. Iran J Psychiatry. 2016;11(3):166-72.

12. Garland EL, Farb NA, Goldin P, Fredrickson BL. (2015). Mindfulness Broadens Awareness and Builds Eudaimonic Meaning: A Process Model of Mindful Positive Emotion Regulation. Psychol Inq. 2015;26(4):293-314. https:// doi.org/10.1080/1047840X.2015.1064294.

13. Hidano T, Fukuda M, Iwawaki S, Soga Y, Spielberger CD. State-Trait Anxiety Inventory-Form JYZ Manual. Tokyo: Jitumukyouiku-Shuppan; 2000.

14. Fukuda K, Kobayashi S. Self-Rating Depression Scale. Psychiatria et Neurologia Japonica. 1973;75(10):673-9.

15. Asakura S, Inoue S, Sasaki F, Sasaki Y, Kitagawa N, Inoue T, Denda K, Koyama T, Ito M, Matsubara R. Reliability and validity of the Japanese version of the Liebowitz Social Anxiety Scale. Seishin Igaku. 2002;44(10):1077-84.

16. Kaiya H, Kanai Y, Kumano H, Sakano Y. Development and Validation of the Tokyo University Social Anxiety Scale (TSAS). Japanese Journal of Psychosomatic Medicine. 2004;44(4):279-87.

17. Kabat-Zinn J. Full catastrophe living: Using the wisdom of your mind and body to face stress, pain, and illness. New York: Delacorte; 1990.

18. Walach $\mathrm{H}$, Buchheld N, Buttenmüller V, Kleinknecht N, Schmidt S. Measuring mindfulness $₫$ the freiburg mindfulness inventory (FMI). Personality Individ Differ. 2006;40(8):1543-55.

19. Delmonte MM. Mindfulness and awareness: Constructivist, psychodynamic and Eastern perspectives. International Journal of Mental Health Addiction. 2012;10(3):311-29.

20. Morrison AS, Mateen MA, Brozovich FA, Zaki J, Goldin PR, Heimberg RG, Gross JJ. Changes in Empathy Mediate the Effects of Cognitive-Behavioral Group Therapy but Not Mindfulness-Based Stress Reduction for Social Anxiety Disorder. Behav Ther. 2019;50(6):1098-111. https://doi.org/10.1016/j.beth.2019.05.005.

21. Goldin PR, Morrison AS, Jazaieri H, Heimberg RG, Gross JJ. (2017) Trajectories of social anxiety, cognitive reappraisal, and mindfulness during an RCT of CBGT versus MBSR for social anxiety disorder. Behav Res Ther. 2017;97:1-13. https://doi.org/10.1016/j.brat.2017.06.001.

22. Dahl CJ, Lutz A, Davidson RJ. Reconstructing and deconstructing the self: cognitive mechanisms in meditation practice. Trends Cogn Sci. 2015;19(9):515-23. https://doi.org/10.1016/j.tics.2015.07.001.

23. Kirk A, Broman-Fulks JJ, Arch JJ. A Taxometric Analysis of Experiential Avoidance. Behav Ther. 2021;52(1):208-20. https://doi.org/10.1016/j.beth.2020.04.008.

24. Bornemann B, Singer T. Taking time to feel our body: Steady increases in heartbeat perception accuracy and decreases in alexithymia over 9 months of contemplative mental training. Psychophysiology. 2017;54(3):469-482.https://doi.org/10.1111/psyp.12790.

25. Aaron RV, Blain SD, Snodgress MA, Park S. Quadratic Relationship Between Alexithymia and Interoceptive Accuracy, and Results From a Pilot Mindfulness Intervention. Front Psychiatry. 2020;10(11):132. https://doi.org/10.3389/fpsyt.2020.00132. 
26. APA Dictionary of Psychology. https://dictionary.apa.org/catharsis.

27. Delmonte MM. Mindfulness and awareness: Constructivist, psychodynamic and Eastern perspectives. International Journal of Mental Health Addiction. 2012;10(3):311-29.

28. Delmonte MM. Meditation, the unconscious, and psychosomatic disorders. Int J Psychosom. 1989;36(1-4):45-52.

29. DelMonte MM. Meditation and the unconscious. J Contemp Psychother. 1995;25(3):223-42. https://doi.org/10.1007/BF02306630.

30. Kurth F, MacKenzie-Graham A, Toga AW, Luders E. Shifting brain asymmetry: the link between meditation and structural lateralization. Social cognitive and affective neuroscience. $2015 \mathrm{Jan}$ 1;10(1):55-61. https://doi.org/10.1093/scan/nsu029.

31. Luders E, Clark K, Narr KL, Toga AW. Enhanced brain connectivity in long-term meditation practitioners. Neuroimage. 2011;57(4):1308-16. https://doi.org/10.1016/j.neuroimage.2011.05.075.

32. Luders E, Phillips OR, Clark K, Kurth F, Toga AW, Narr KL. Bridging the hemispheres in meditation: thicker callosal regions and enhanced fractional anisotropy (FA) in long-term practitioners. Neuroimage. 2012;61(1):181-7. https://doi.org/10.1016/j.neuroimage.2012.02.026.

33. American Psychiatric Association. Diagnostic Statistical Manual of Mental Disorders, 4th Edition Text Revision. Washington, DC: American Psychiatric Association; 2000.

34. Tedeschi RG, Calhoun LG. Target Article: "Posttraumatic Growth: Conceptual Foundations and Empirical Evidence". Psychol Inq. 2004;15(1):1-18. https://doi.org/10.1207/s15327965pli1501_01.

35. Engel K. Meditation. Vol. II. Empirical Research and Theory. Meditation vol.2, Peter Lang, Frankfurt; 1997.

36. Ryan RM, Deci EL. On happiness and human potentials: A review of research on hedonic and eudaimonic well-being. Annu Rev Psychol. 2001;52:141-66.

37. Garland EL, Hanley AW, Goldin PR, Gross JJ. Testing the mindfulness-to-meaning theory: Evidence for mindful positive emotion regulation from a reanalysis of longitudinal data. PLoS ONE. 2017;12(12):1-19. https://doi.org/10.1371/journal.pone.0187727.

38. Garland EL, Fredrickson BL. Positive psychological states in the arc from mindfulness to selftranscendence: extensions of the Mindfulness-to-Meaning Theory and applications to addiction and chronic pain treatment. Curr Opin Psychol. 2019;28:184-91. https:// doi.org/10.1016/j.copsyc.2019.01.004.

\section{Figures}




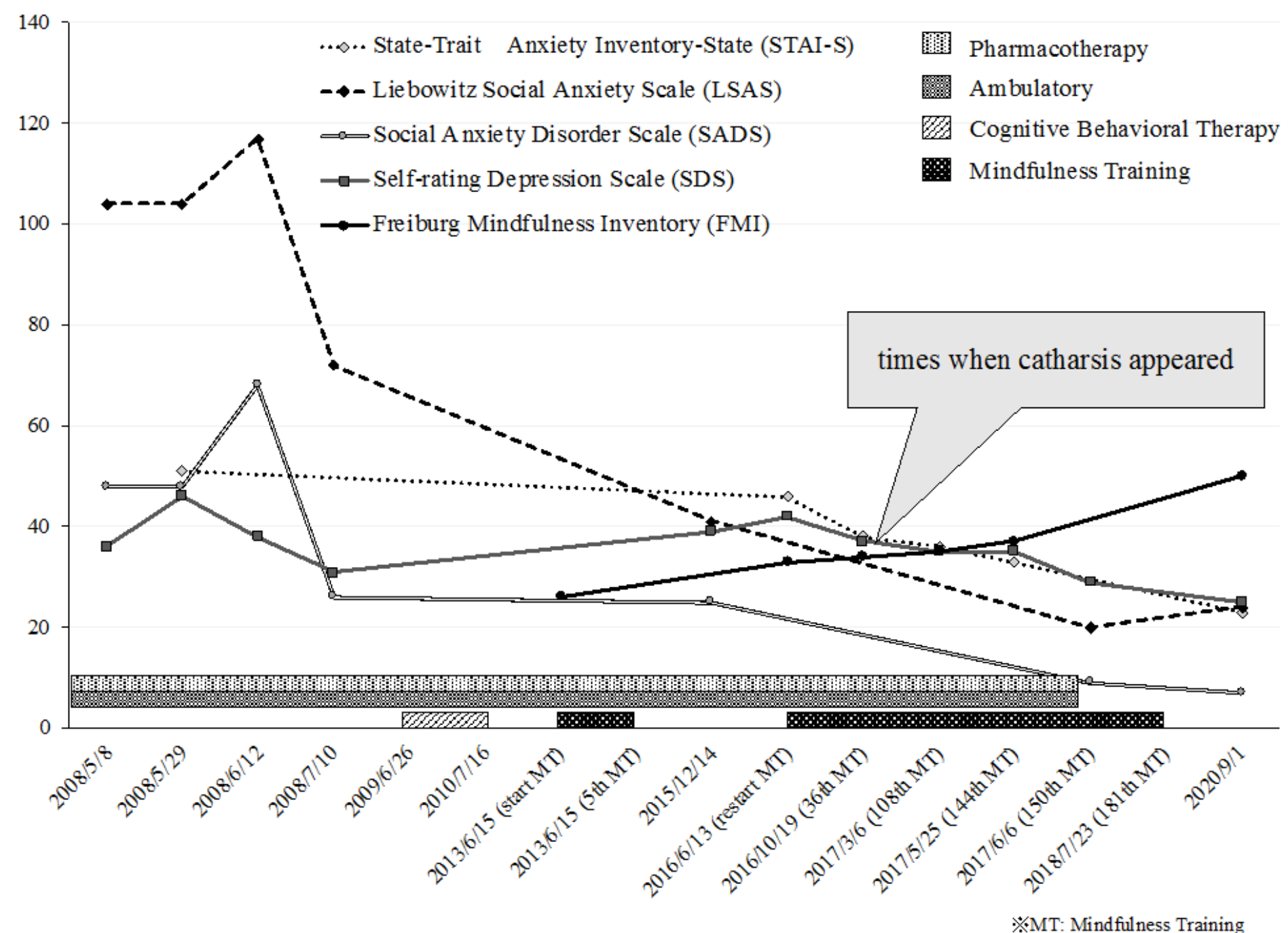

\section{Figure 1}

Clinical course of Mrs. A 